\title{
Identification and Evaluation of the Effective Criteria on Customer Satisfaction with Kitchen Worktops Product
}

\author{
Vahid Nabavi, Majid Azizi, Nemat Allah Mohebbi \\ University of Tehran, Tehran, Iran. \\ Email: vahidnabavi@ut.ac.ir,mazizi@ut.ac.ir,mohebbi.nemat@yahoo.com
}

Received May $19^{\text {th }}, 2012$; revised June $13^{\text {th }}, 2012$; accepted July $27^{\text {th }}, 2012$

\begin{abstract}
In cycle of attraction and keeping the customers, fulfilling the customer satisfaction via identifying of their needs is very important. So, identifying the amount of customer satisfaction and informed of the field of strength and weakness in this regard, helps manager programming in line with customers better maintenance. The objective of this study is determination and priority of effecting criteria on customer satisfaction of worktops product. For this purpose, after preliminary investigation and interviews with experts and worktops customers, the effective criteria were identified. Then the priority rates (weighting value) of obtained criteria and sub-criteria were determined by Analytical Hierarchy Process (AHP). On the base of obtained results the criteria of selling and price condition, delivery condition, payment condition, the quality of CPL veneer, the quality of used MDF and lead time of product have the highest priorities, respectively.
\end{abstract}

Keywords: Customer Satisfaction; Criteria; Priority; Analytical Hierarchy Process (AHP); Worktops Product

\section{Introduction}

With a rapid change from traditional industrial, wood industry in Iran has tried to reduce the gap with other countries for long and during this transition; it should become also updated and efficient in various areas of management and customer care, while enjoying a variety of development tools in the field of new machinery and technologies. The contemporary era is associated with features such as supply abundance, competition expansion, technological developments, globalization and etc., some achievements of which for customers are the explosion of selections, increase of the bargaining power and achieving greater value in favor of which this equation still moves. Intensification of competitive environment in global and national trade in most countries, with the aim of attracting new customers and retaining existing customers, has increased the concerns of senior managers of the organizations and large and small companies. Strengthening the privatization process and prioritization of the principle forty-four of the constitution in Iran along with globalization, has enhanced this competition, especially in Iran, where many manufacturers are producing this product. Thus, to improve quality and increase the competitive power, the organizations should identify the key needs affecting the customers' satisfaction improvement and consider them in the product according to their importance level. Today, kitchen worktops manufacturing industry is one of the largest sectors of the wood industry in Iran and it has doubly flourished in recent years considering the population increase and consequently, the increase of the manufacturing. In this research, identification and evaluation of the criteria affecting customer satisfaction kitchen worktops product has been studied. There are different methods to measure customer satisfaction and weight the factors affecting satisfaction among which Analytic Hierarchy Process is used in this study. Using some conventional statistical models such as multiple linear regression and cluster analysis, Varva [11] introduced some methods to measure customer satisfaction. In this model, general and partial customer satisfaction will be calculated according to their judgments. Zaribaf and Roushani [14] designed a model to measure customer satisfaction and used it in rubber industry. In their study, the criteria affecting customer satisfaction were first identified and then, weighted based on AHP. Saidi and Mehrabian [8] measured the satisfaction level of end users of Rafsanjan Pistachio Company using AHP. Using this method, the influential parameters were first determined through which the satisfaction level of end users was measured. In a study, Firouzian et al. ([3] weighted and ranked the factors affecting customer satisfaction in the automotive industry using the Analytical Hierarchy Process (AHP). In this study, the factors affecting customer satisfaction were first identified using the existing resources and opinions of technical experts of Saipa Company and criterion hierarchy was designed. 
Then, using questionnaire, the required data was collected and analyzed through Expert Choice software. Jeong and Lee [13] introduced the results of analysis of the factors affecting the satisfaction of e-shopping furniture customers to be product diversity, the quality of services, accountability and interaction and announced customer satisfaction as an effective factor in customer's loyalty in e-shopping. Designing a model, Sharbatoqli and Ekhlasi [10] managed to measure the satisfaction level of customers of Bank of Industry and Mine. Lee and Kozar (2006) through applying an analytic hierarchy process investigates websites quality factors, their relative importance in selecting the most preferred website and the relationship between website preference and financial performance, The study identified different relative importance of each website quality factor and priority of alternative websites across e-business domains and between stakeholders. This study also found that the website with the highest quality produced the highest business performance. Kwong and Bai [5] determined the importance weights for the customer requirements in quality function deployment using a fuzzy AHP with an extent analysis approach. Vanegas and Labib [12] proposed a method to determine the weights for the customer requirements by converting the weights from the Analytic Hierarchy Process (AHP) into fuzzy numbers using the concept of a "fuzzy line segment". The present study, aiming to identify and evaluate the criteria affecting the customer satisfaction with kitchen worktops product intends to answer the question of what are the most important factors influencing the satisfaction of the customers of this product? According to the above question, it can be assumed that the indices of the product price, fast delivery of the product and payment terms of the amount of the product are of the highly important criteria in customer satisfaction.

\section{Research Methods}

\subsection{Identifying the Parameters Affecting Customer Satisfaction}

In the first stage, in order to identify the parameters affecting customer satisfaction, after library studies, inquiry and interviews with experts and manufacturers as well as the customers of kitchen worktops, 19 effective criteria were identified (Appendix 6). These criteria were classified into 5 main categories as follows:

1) Price and sales terms: This criterion shows the advantages of price and sales terms of the product compared to the competitors and quality of the product;

2) After sales services: It includes the company's adherence and commitment towards buyers;

3) Delivery terms: This criterion includes the quality of the product delivery to the customers under agreements between the company and customers.

4) The quality of the consumed raw materials: Including the quality of the raw materials used in manufacturing the product;

5) Technical features of the product: The specifications of the manufactured product in terms of application and compliance with the requirements of consumers were classified in this group.

And the hierarchy of these criteria was designed according to Figure 1. In the next stage, to determine the weighted value and prioritize criteria and sub-criteria, a questionnaire was designed for paired comparison of them and it was distributed among 5 experts working in the wood industry and 10 major retailers and consumers of this product, and completed by them. All under question experts have had undergraduate and postgraduate education in the field of wood industry and have been working in wood industry and manufacturing between 3 to 13 years, they are also 10 seller and consumers with 5 to 15 years of experience sales of kitchen worktops product, representing different manufacturers and the construction and installation of kitchen worktops and have experience in different parts of the country. Then, the results of the questionnaires were collected and analyzed in the environment of Choice Expert software and weighted value of each of the following criteria and sub-criteria was determined.

\subsection{Analytical Hierarchy Process}

Analytical Hierarchy Process is one of the most efficient decision making and weighting methods, which was first presented By Tomas L. Saaty in 1980 [4]. This method is established based on paired comparison and allows the managers to evaluate and compare various scenarios. To measure the weight of each of the criteria and sub-criteria, first the geometric mean of importance degrees will be calculated for each of the paired comparison matrix cells the formula of which is [1]:

Collective judgment:

$$
\begin{gathered}
a_{12}=\left(a_{12} 1 \times a_{12} 2 \times \cdots \times a_{12} N\right)^{\frac{1}{n}} \\
{\left[\begin{array}{cccc}
w_{1} / w_{1} & w_{1} / w_{2} & \cdots & w_{1} / w_{n} \\
w_{2} / w_{1} & w_{2} / w_{2} & \cdots & w_{2} / w_{n} \\
\vdots & \vdots & \cdots & \vdots \\
w_{n} / w_{1} & w_{n} / w_{1} & \cdots & w_{n} / w_{n}
\end{array}\right] \Rightarrow\left[\begin{array}{c}
w_{1}\left(\sum_{i=1}^{n} 1 / w_{1}\right) \\
w_{2}\left(\sum_{i=1}^{n} 1 / w_{i}\right) \\
\vdots \\
w_{3}\left(\sum_{i=1}^{n} 1 / w_{i}\right)
\end{array}\right]}
\end{gathered}
$$


Satisfaction with Kitchen Worktops Product

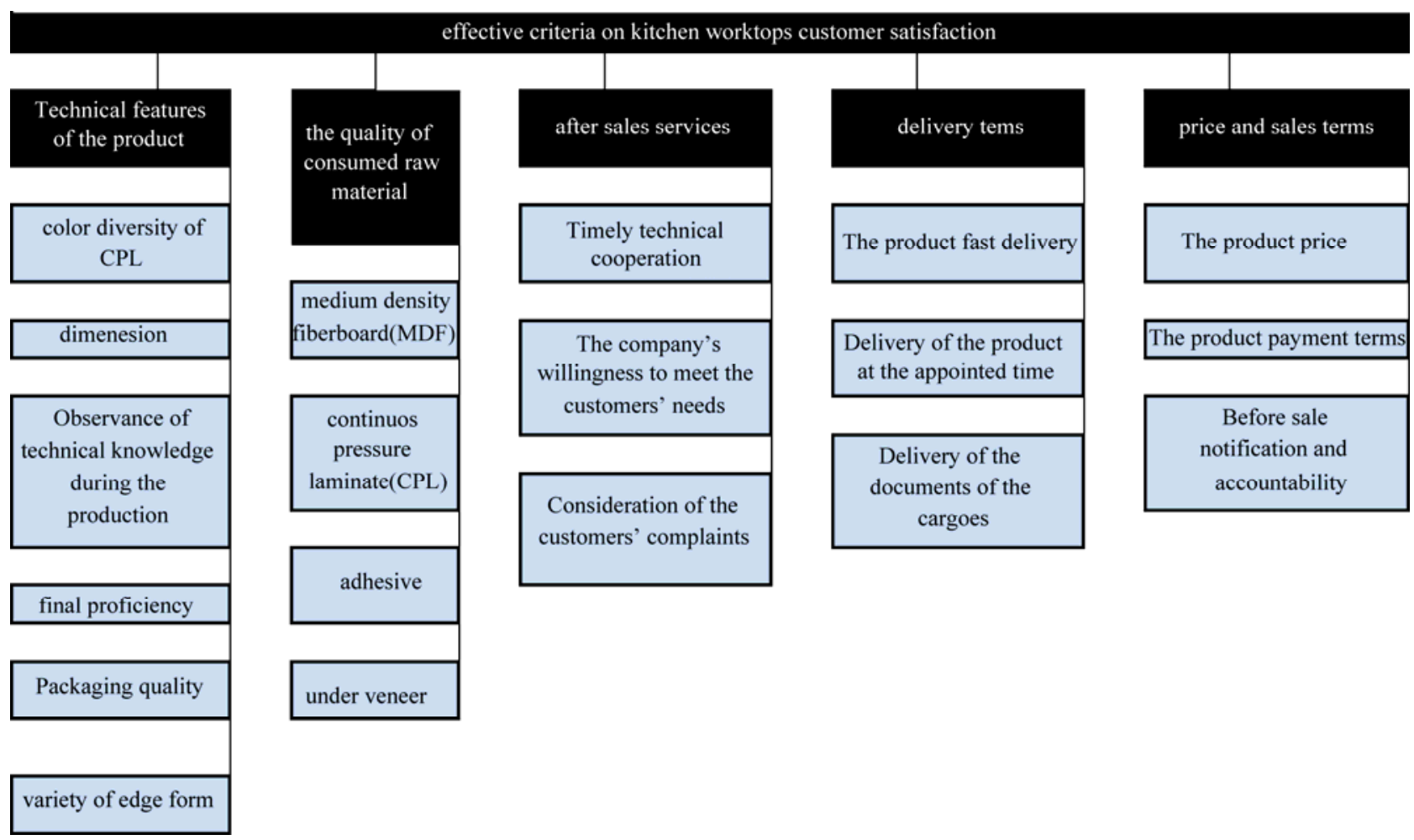

Figure 1. Hierarchy of the criteria and sub-criteria affecting the kitchen worktops customer satisfaction.

After calculating the geometric mean of all paired comparison matrix cells, the results will be normalized and criteria and sub-criteria will me weighted by combining weights of low level elements and high level elements in the hierarchy. An important point about the paired comparison matrix is their inconsistency rate, which should be $\leq 0 / 1$ in order for the judgments to be stable. Therefore, if this rate is greater than $0 / 1$ in some paired comparison matrices, the relevant expert needs repeat his judgment and then calculate the geometric mean of paired comparison matrix cells [7].

\section{Results}

The results of weighting each criterion affecting the kitchen worktops customer satisfaction will be presented in this section through Expert Choice software. In addition, the synthesis results of the second level are given in Appendixes 1 to 5 .

\section{Results Analysis}

The overall inconsistency rate of the matrices is 0.01 , indicating high stability and compatibility of the results. These results indicate that among the main criteria, the criterion of price and sales terms and quality of the used raw material is the most important in the kitchen worktops customer satisfaction (Figures 2 and 3). The results of weighting and the matrix of paired comparisons of subcriteria related to each criterion are given in Appendixes 1 to 5 .

\subsection{Criteria Analysis (First Level)}

\subsubsection{Price and Sales Terms (0.362)}

According to Figure 3, the price and sales terms has the highest weight among the criteria affecting kitchen worktops customer satisfaction. Considering the high capacity of manufacturers of this product and consequently, highly competitive market of this product in the country, the most important effective factor in attracting customer satisfaction is price and sales terms of the product. According to the experts and respondents in this survey, in cases when there is a similar product with different brands in the kitchen worktops market, price of the product and its payment terms is considered a very important factor to attract and maintain the customers satisfaction and represents high elasticity of the product. There is a direct relationship between changes in product prices and satisfaction. It means that the increase in customer satisfaction is likely to be associated with a decline in the product price [2].

\subsubsection{Quality of Raw Materials with a Weight of (0.237)}

One of the most important principles in customer satisfaction is to use high quality raw materials in manufacturing 
Numerical Assessment

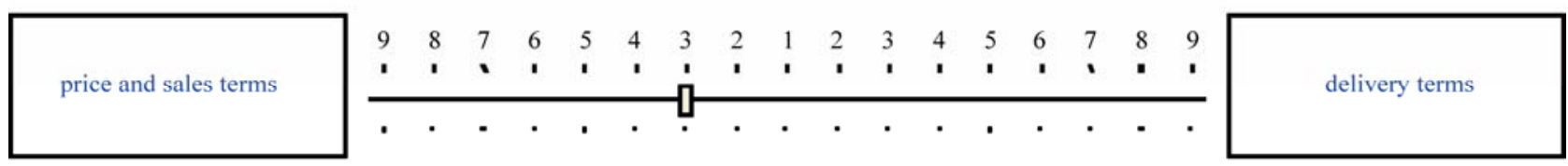

Compare the relative importance with respect to: worktops customer satisfaction

\begin{tabular}{|l|l|r|r|r|r|r|}
\hline & Price and sales terms & delivery terms & After sales raw material quality & \multicolumn{1}{c|}{ technicalfeatures } \\
\cline { 2 - 6 } & & 2.61696 & 4.82368 & 1.55172 & 2.03216 \\
Price and sales terms & & & 3.32719 & $(1.35536)$ & $(1.05909)$ \\
\hline delivery terms & & & & $(3.56019)$ & $(2.59584)$ \\
\hline $\begin{array}{l}\text { After sales services } \\
\text { Thrquality of raw material }\end{array}$ & & & & & 1.59489 \\
\hline technicalfeatures & Incon: 0,01 & & & & \\
\hline
\end{tabular}

Figure 2. The results of the geometric mean of the paired comparison matrix of the criteria (first level).

Priorities with respect to
worktops customer satisfaction
Price and sales terms
The quality ofraw material
delivery terms
Technical features of the product
After sales services
Inconsistency $=0.00653$
with 0 missing judgments

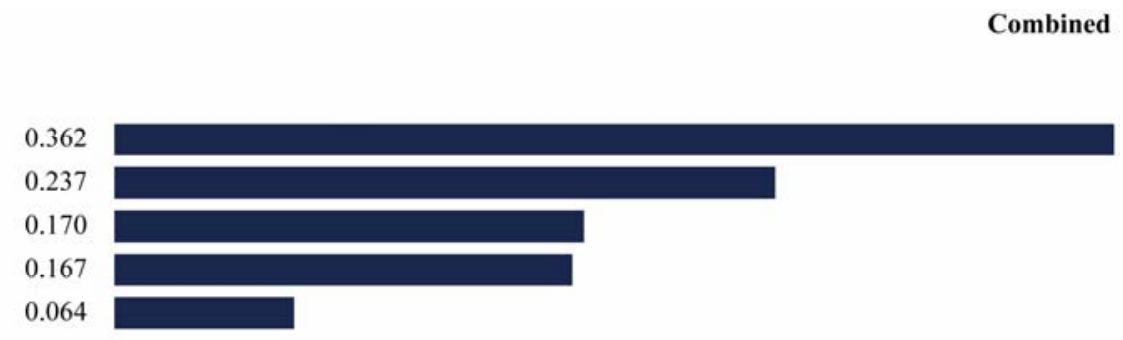

Figure 3. The results of weighting the criteria affecting the customer satisfaction (first level) (inconsistency rate $=0.01$ ).

the product. Different characteristics of high quality raw materials will physically reduce wastes during the production process and will reduce production costs of the kitchen worktops and cost price of the product. This factor also increases the level of utility and durability of the final product. Since kitchen worktops are located in the moist environment of kitchen, they are always exposed to damaging factors such as moisture, detergents and stroke. Thus, these factors will necessitate that the raw material used in the products construction should be of high quality so that they could maintain their original characteristics over time during their application. However, considering the higher prices of higher quality raw materials, the increase in the quality of used raw materials will certainly affect the cost price. Also based on the results of analysis of the first level paired comparison questionnaire, the delivery terms of the product weighing 0.17 and technical characteristics of the product weighing 0.167 are almost equally important in kitchen worktops customer satisfaction.

\subsection{Final Weighting of the Sub-Criteria (Figure 4)}

\subsubsection{Price}

This criterion, weighting 0.17 , is the most important factor in the increase of customer satisfaction. The presentation of a product better than that of other competitors and the use of proper steps in choosing a strategy to achieve a favorable position against competitors is of the important principles to gain profit in business. Thus, a company should be able to price its products so that it could earn incomes commensurate with the value presented to the customers and thereby, maintain its position to customers, complementary products, competitors and potential newcomers. As Saidi and Mehrabian (2007) claim, the company's pricing policy can affect the competitive form and nature the company is facing. A company's management will usually determine the sales price so that it covers all costs of production, distribution and sales, for the effort and the risks incurred, while also receiving a fair profit. Thus, the price of a company's product is a determinant factor in demand of that product; so that among sub-criteria related to the price and sales conditions, the product price is the most important factor.

\subsubsection{Payment Terms of the Product}

This Sub-criterion weighing 0.114 is the second factor affecting kitchen worktops customer satisfaction. Considering the high number of kitchen worktops manufacturers in the country, the manufacturer companies find different ways to sell more and increase market level. In these conditions, for success in the market, the companies 


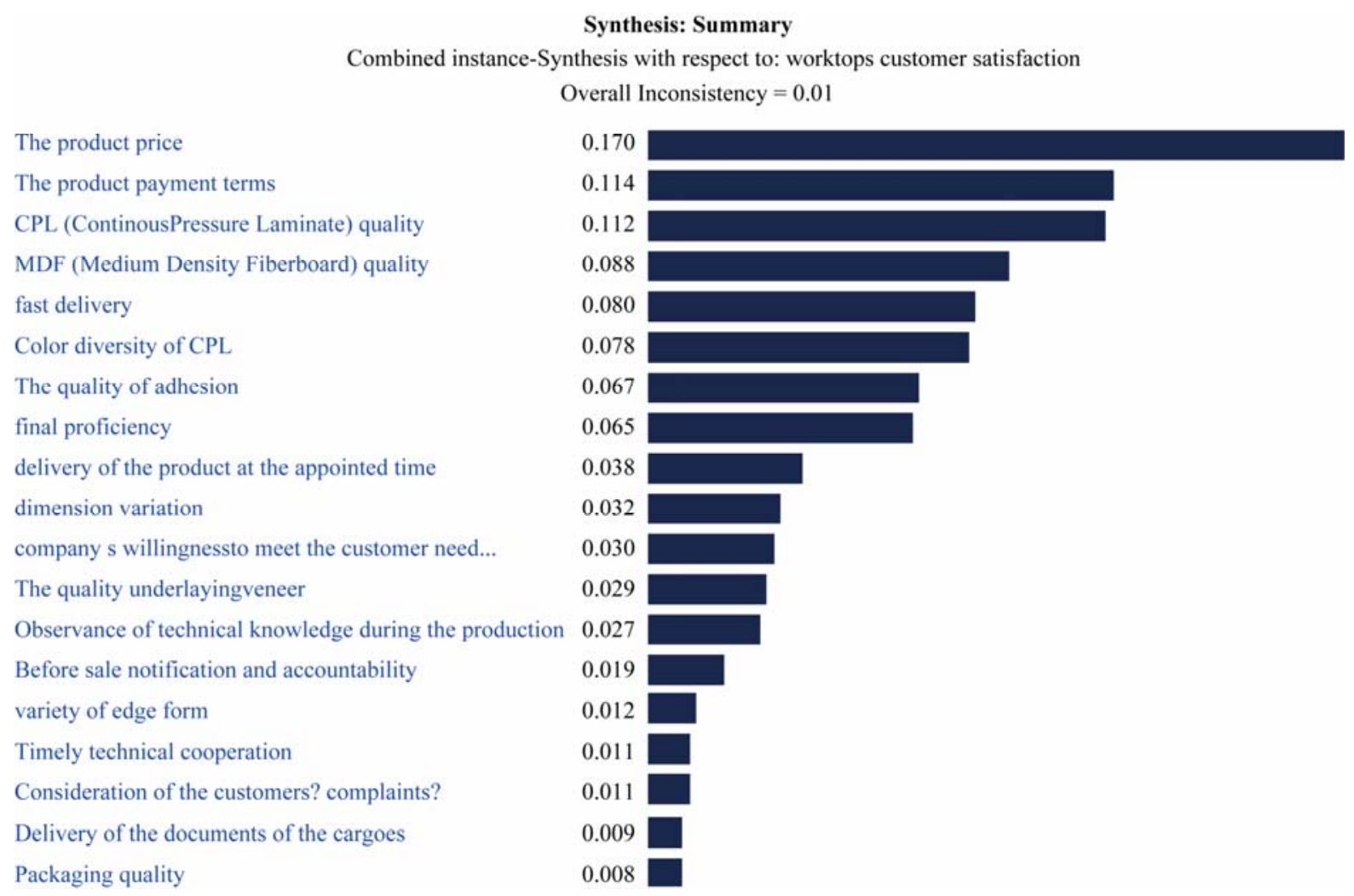

Figure 4. The final prioritization of the criteria affecting the kitchen worktops customer satisfaction.

offer sales and delivery services as well as better payment terms including low down payment, low interest or even interest-free long-term installments to their customers in order to sell their products [3]. On the other hand, considering poor liquidity of the customers, applying these methods attracts more customers and ensures their satisfaction.

\subsubsection{Quality of the Surface Veneer (CPL)}

This Sub-criterion indicating the level of quality and importance of a type of surface coating used in manufacturing kitchen worktops, weighting 0.112 , is the third important factor in customer satisfaction. The surfaces in sight and in fact, the applicable surfaces of the kitchen worktops will be completely covered with Continuous Pressure Laminate (CPL) veneer, so that the final durability and efficiency of this product is highly dependent on the surface coating. The use of high quality coatings is effective in customer satisfaction, due to their high durability, beauty and good function. On the other hand, since a high percentage of the cost price of is related to the raw materials, its high quality reduces wastes during production and duplications and thereby, reduces the cost price of the final product, which in turn will have other indirect effects on customer's final satisfaction. However, this sub-criterion is of paramount importance among the sub- criteria related to the quality of raw materials.

\subsubsection{Medium Density Fiberboard (MDF) Quality}

This factor is the fourth factor affecting kitchen worktops customer satisfaction of which high volume of kitchen worktops final product is composed. Like coating and CPL, it is also highly effective in the cost price of the product. Mechanical resistance, moisture resistance, durability and winding feature are of the factors affecting the satisfaction of the product customers. For example, moisture causes swelling in the boards and eventually leads to the loss of the kitchen worktops in the moist environment of the kitchen. Moisture resistance of various MDF (Medium Density Fiberboard) is different. According to their application type, this difference leads to the preference of one type of MDF to the other one, and increase or reduction of utility of a specific type of them (Rafighi and Moradi [6]).

\subsubsection{Fast Delivery}

Fast delivery of product to the customer according to the specifications demanded by the customer is the fifth factor affecting customer satisfaction. Since customers receive this product by order and creating some conditions in the company to achieve fast delivery of the product to the customer can have great impact on customer satisfaction. 
However, fast delivery is of highest important among the sub-criteria related to the delivery terms. This shows that despite being ranked fifth in the final analysis, the most important influential factor in the field of delivery terms is fast delivery of the product.

\subsubsection{Three Sub-Criteria with Close Weight}

Color variety of veneer, quality of adhesive and adhesion of veneer, and the quality of the product performance by the end users) These three sub-criteria in the final analysis through Expert Choice software weighting respectively $0 / 078,0 / 067$ and $0 / 065$ are in the priorities sixth to eighth. The relatively close weights of these three criteria show the almost similar importance of these three criteria in kitchen worktops customer satisfaction. Presenting various colors and designs of coatings to the kitchen worktops customers and responding to their interests will be an important factor in satisfaction, so that among the subcriteria related to the technical specifications of the product, color variety of coating is of the highest importance and consideration of this issue can have a large impact on customer satisfaction. The quality of coating adhesion to MDF is of highly importance considering being vulnerable. The factor of product efficiency quality by the end users represents the satisfaction level of the product end users and the main kitchen worktops consumer. Given that direct customers of the company are in fact the kitchen worktops sellers to the end users, this criterion shows their satisfaction importance.

\subsubsection{The Company's Willingness to Meet the Customers' Needs}

This sub-criterion which is related to the company's after sales services, although ranked eleventh in the final synthesis weighting $0 / 03$, it is of the highest importance among the sub-criteria related to after sales services. Thus, this sub-criterion should be more considered in warranty related activities. After sales services, which are of the customer relationship management activities, have a large impact in making the customers loyal [11].

\section{Conclusion}

According to studies conducted in this research, which have identified and ranked the factors affecting kitchen worktops customer satisfaction, it can be concluded that in the competitive market of this product in our country, product price and sale terms are the most important factor in the customer satisfaction. It seems that considering that kitchen worktops manufacturing technology is the same in most Iranian manufacturers of this product, in this conditions, low cost price and considering other effective factors can be influential on customer satisfaction. However, considering higher quality products in the market with higher prices, it can be concluded that the price increase which is proportionate to a rise in the quality of other influential factors such as the quality of used raw materials, delivery terms and technical characteristics of the products, will be acceptable for the customers and the competitive advantage of the product will be maintained.

\section{REFERENCES}

[1] G. Varva, "Improving Your Measurement of Customer Satisfaction: A Guide to Creating, Conducting, Analyzing, and Reporting Customer Satisfaction Measurement Programs," ASQ Quality Press, Milwaukee, 1997.

[2] Z. Mehdi, R. Barab and Farrokh, "Designing a Model to Measure Customer Satisfaction and Its Implementation in the Rubber Industry," Journal of Management, Vol. 5, No. 12, 2008, pp. 47-62.

[3] S. Sohail and M. Saeed, "Measurement of Satisfaction Level of End Users of Rafsanjan Pistachio Company through AHP," Journal of Industrial Management, Faculty of Humanities, Vol. 2, No. 3, 2007, pp. 37-48.

[4] F. Mahmoud, M. Moqadaseh and G. Hadi, "Weighting and Ranking the Factors Affecting Customer Satisfaction in the Automotive Industry Using Analytical Hierarchy Process (AHP)," Culture Management, Vol. 4, No. 13, 2006, pp. 37-64.

[5] Y. J. Jeong and Y. S. Lee, "A Study on the Customer Satisfaction and Customer Loyalty of Furniture Purchaser in On-Line Shop," Asian Journal on Quality, Vol. 11, No. 2, 2010, pp. 146-156.

[6] S. Ahmad and E. Amir, "Designing a Model to Measure Customer Satisfaction in the Developmental Banking Industry and Accordingly to Measure Customer Satisfaction of Bank of Industry and Mine," Knowledge Management, Vol. 21, No. 21, 2008, pp. 57-74.

[7] C. K. Kwong and H. Bai, "Determining the Importance Weights for the Customer Requirements in QFD Using a Fuzzy AHP with an Extent Analysis Approach," Journal of Intelligent Manufacturing, Vol. 35, No. 7, 2003, pp. 367-377.

[8] L. V. Vanegas and A. W. Labib, “A Fuzzy Quality Function Deployment (FQFD) Model for Driving Optimum Targets," International Journal of Production Research, Vol. 39, No. 1, 2001, pp. 99-120. doi: $10.1080 / 00207540010005079$

[9] G. Pour and S. Hassan, "Analytical Hierarchy Process (AHP)," Amirkabir University Publication Center, Tehran, 2000.

[10] A. M. Javad, "Multi-Criteria Decision Making," Tehran University Press, Tehran, 1998.

[11] T. L. Saaty, "Fundamentals of Decision Making and Priority Theory," 2nd Edition, RWS Publications, Pittsburgh, 2000 .

[12] E. Anderson, "Customer Satisfaction and Price Tolerance," Marketing Letters, Vol. 7, No. 3, 1996, pp. 265-274. doi:10.1007/BF00435742 
Satisfaction with Kitchen Worktops Product

[13] F. Mahmoud, M. Moqadaseh and G. Hadi, "Weighting and Ranking the Factors Affecting Customer Satisfaction in the Automotive Industry Using Analytical Hierarchy Process (AHP)," Culture Management, Vol. 4, No. 13, 2006, pp. 37-64.
[14] M. Kobra and R. Ali, "Determination and Evaluation of the Factors Affecting the Use of MDF Wood Products," Wood and Paper Industry, Vol. 8, No. 45, 2009, pp. 3437. 


\section{Attachments}

Numerical Assessment

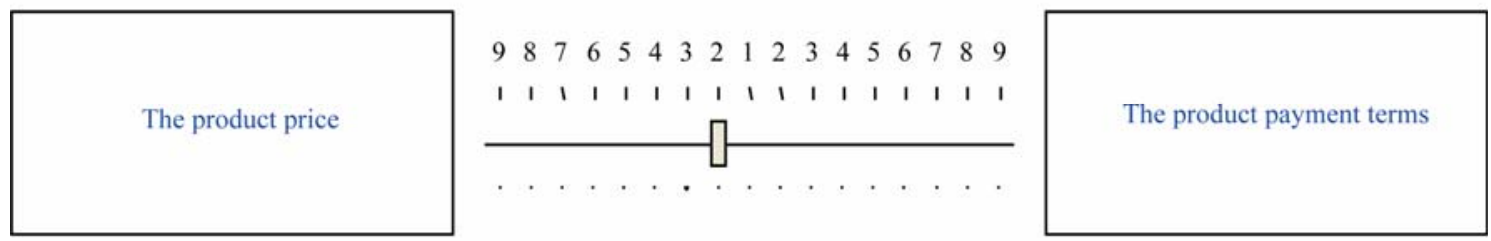

Compare the relative importance with respect to: price and sales terms

\begin{tabular}{|c|c|c|c|}
\hline & price & payment & Before sale notification and accountability \\
\hline The product price & & 1.64541 & 8.11673 \\
\hline The product payment terms & & & 6.60314 \\
\hline Before sale notification and accountability & Incon: 0.01 & & \\
\hline
\end{tabular}

Appendix 1.1. The result of geometric mean of the paired comparison matrix to the criterion of sales and price terms (incompatibility rate $\mathbf{0 . 0 1}$ ).

Priorities with respect to:

Combined worktops customer satisfaction

>price and sales terms

The product price

0.561

The product payment terms

Before sale notification and accountability

0.376

Inconsistency $=0.00901$

with 0 missing judgments.

Appendix 1.2. The diagram of prioritization of sub-criteria of sales and price terms.

Numerical Assessment

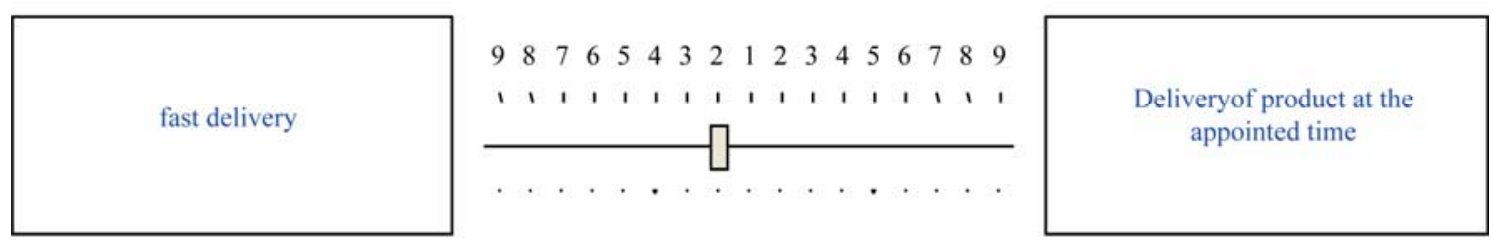

Compare the relative importance with respect to: delivery terms

\begin{tabular}{|c|c|c|c|}
\hline \multirow[b]{2}{*}{ fast delivery } & \multirow[t]{2}{*}{ fast delivery } & \multicolumn{2}{|c|}{ Delivery of the product Delivery of the documents of the cargoes } \\
\hline & & 2.48561 & 7.58618 \\
\hline Delivery of the product at the appointed time & & & 5.26697 \\
\hline Delivery of the documents of the cargoes & Incon: 0.03 & & \\
\hline
\end{tabular}

Appendix 2.1. The result of geometric mean of the paired comparison matrix to the criterion of delivery terms (inconsistency rate 0.03$)$.

Priorities with respect to:

Combined

worktops customer satisfaction $>$ delivery tems

The product fast delivery

0.628

Delivery of the product at the appointed time $\quad 0.303$

Delivery of the documents of the cargoes $\quad 0.069$

Inconsistency $=0.03$

with 0 missing judgments.

Appendix 2.2. The diagram of prioritization of sub-criteria of the product delivery terms. 
Numerical Assessment

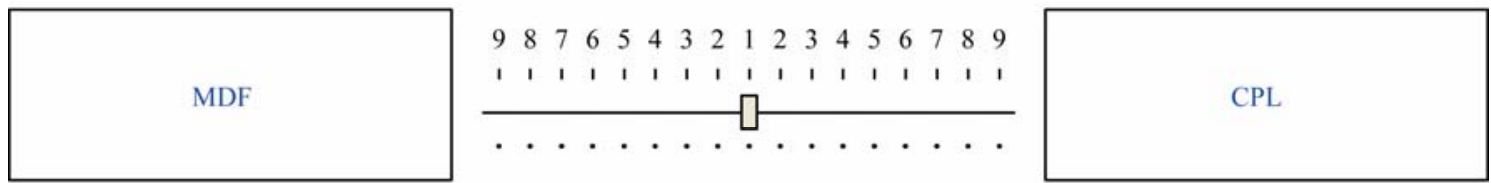

Compare the relative importance with respect to: raw material quality

\begin{tabular}{|l|l|r|r|r|}
\hline & MDF & CPL & adhesive & under veneer \\
\hline MDF & & $(1.21064)$ & 1.43356 & 2.60876 \\
\hline CPL & & & 1.52584 & 4.40932 \\
\hline adhesive & & & & 2.28419 \\
\hline under veneer & Incon: 0.01 & & & \\
\hline
\end{tabular}

Appendix 3.1. The result of geometric mean of the paired comparison matrix to the criterion of raw materials quality (inconsistency rate 0.01 ).

Priorities with respect to: worktops customer satisfaction

>raw material quality

CPL (ContinousPressure Laminate) MDF (Medium Density Fiberboard) adhesive

under veneer

Inconsistency $=0.00554$

with 0 missing judgments.

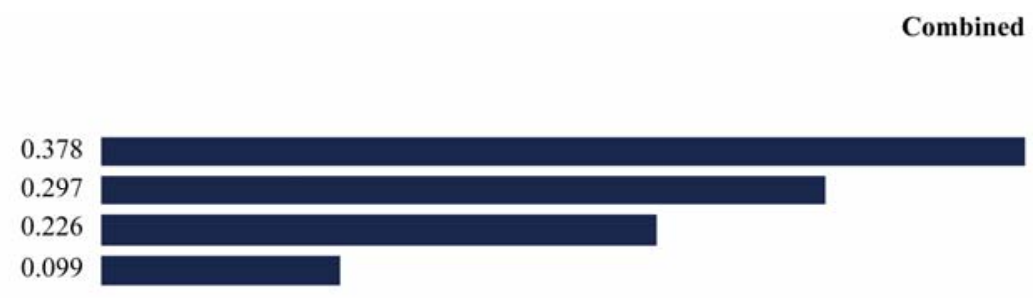

Appendix 3.2. The diagram of prioritization of sub-criteria of raw material quality.

Numerical Assessment

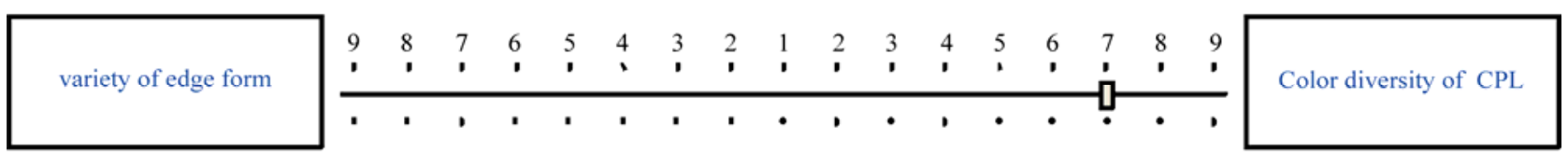

Compare the relative importance with respect to: technological specification

\begin{tabular}{|c|c|c|c|c|c|}
\hline variety of edge form & Color diversity of CPL & dimension variation & Observation of technical knowledge & final proficiency & packing quality \\
\hline 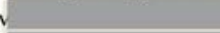 & $(6.83795)$ & $(3.67975)$ & $(1.87154)$ & $(5.68516)$ & 1.60786 \\
\hline$\sqrt{ }$ & & 3.46473 & 2.92419 & 1.03168 & 7.34872 \\
\hline d & & & 1.21064 & $(2.24965)$ & 4.33428 \\
\hline ts & & & & $(1.81187)$ & 3.49626 \\
\hline$f$ & & & & & 8.09709 \\
\hline Incon: 0,01 & & & & & \\
\hline
\end{tabular}

Appendix 4.1. The geometric mean of the paired comparison matrix product technical specification (inconsistency rate of 0.01).

Priorities with respect to:

worktops customer satisfaction

$>$ Technical features of the product

color diversity of $\mathrm{CPL}$

final proficiency

dimension variation

Observance of technical knowledge during the production

variety of edge form

Packaging quality

Inconsistency $=0.01$

with 0 missing judgments.
Combined

0.352
0.292
0.144
0.123
0.052
0.036

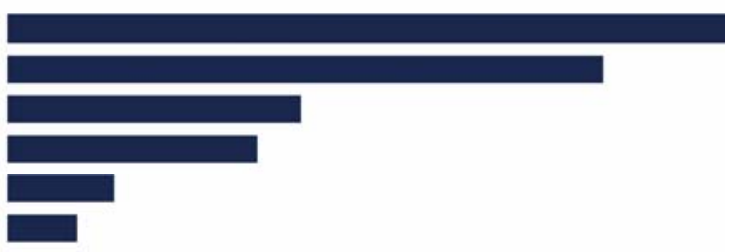

Appendix 4.2. The diagram of prioritization of sub-criteria of technical characteristics of the product. 
Numerical Assessment

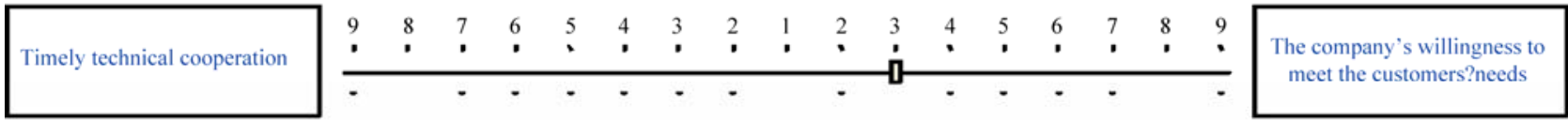

Compare the relative importance with respect to: after sales services

\begin{tabular}{|l|l|c|c|}
\hline & Timely technical cooperation & Company s willingness to meet customer needs & Consideration of the customers?complaints \\
\cline { 2 - 4 } & & & $(2.7159)$ \\
\hline $\begin{array}{l}\text { Timely technical cooperation } \\
\text { Company s willingness to meet }\end{array}$ & & & 1.02238 \\
\hline \begin{tabular}{l} 
Consideration of the customers?complaints \\
\hline
\end{tabular} & Incon: 0.00 & 2.73207 \\
\hline
\end{tabular}

Appendix 5.1. The result of geometric mean of the paired comparison matrix to the criterion of after sales services (inconsistency rate 0.00$)$.

Priorities with respect to: worktops customer satisfaction $>$ after sales services

The company's willingness to meet the customers? needs Timely technical cooperation

Consideration of the customers? complaints

Inconsistency $=0.00003$

0.210

with 0 missing judgments.

Appendix 5.2. The diagram of prioritization of sub-criteria of after-sale service. 


\section{Appendix 6. Descriptions of sub-criteria.}

\section{Sub-criteria}

The product price

The product payment terms

Before sale notification and accountability

The company's willingness to meet the customers' needs

The product fast delivery

Delivery of the product at the appointed time

Delivery of the documents of the cargoes

Timely technical cooperation

Diversity of the product edge form

Color diversity of coating

Observance of technical knowledge during the production

Packaging quality

The quality of the used MDF

The quality of CPL

The quality of the underlying veneer

Dimensions

The quality of adhesion

The quality of the product's efficiency by the customer (final proficiency)

Consideration of the customers' complaints
Descriptions

It is the amount paid by the costumer for having goods and its associated services.

In the common transactions in the market, the manufacturers determine various conditions for getting the product price according to the product type. It includes in cash and Installment.

The costumers do a research on technical conditions of the product or sales before the purchase and the notification method will contribute to the customer satisfaction.

Regarding this specific product (kitchen worktops), sometimes the customers present certain expectations such as: the use of a certain type of raw materials or delivery in less time and etc... which are highly effective in the customer satisfaction.

Due to the one-off production of this product in most companies, there is an interval between the order and the delivery.

This criterion means to deliver at the appointed time and location and based on the agreed conditions.

Sending the list of products with full details (size. Color, coating, model and...) along with the cargo sent to the customers as well as the instructions on transportation, maintenance and usage.

Responding to the customers' questions regarding the use of the product or removal of the probable problems or notification about the similar or substitute products.

Post-formed kitchen worktops are highly various in terms of initial form which are to respond to the different tastes of the customers.

Kitchen worktops are covered with CPL coating which has various colors (design of wood and stone and...)

Using the new technology and techniques during the production including putting the dropper's groove, preventing twisting of the product and lack of using nail to attach MDF pieces.

Packaging type and using the customers' viewpoint and requirements in it.

The main substance in construction of this product is MDF the quality of which is important in the efficiency and durability of the product.

Kitchen worktops surfaces are exposed to stroke, chemicals, heat, friction, UV radiation and ..., the resistance and durability of the product in these cases are dependent on the coating quality.

The surface below these worktops are covered with water-proof paper or CBL coating.

Width, thickness, length and detailed observance of these dimensions in the final product according to the customer's order.

The criterion of the proper adhesion of coating to the MDF in the surface and edges is also an effective factor in the level of kitchen worktops customer satisfaction.

Most of the criteria affecting kitchen worktops customer satisfaction are related to its after installation such as durability of the water proof strip of the dropper or not losing the coatings' edges or not wrapping the worktops due to the conditions of heat and moisture of the installation location.

Consideration of the customers' complaints as soon as possible and appropriate accountability. 